University of New Hampshire

University of New Hampshire Scholars' Repository

3-1-2016

\title{
State and Local Determinants of Employment Outcomes among Individuals with Disabilities
}

\author{
Purvi Sevak \\ Mathematica Policy Research \\ John O'Neill \\ Kessler Foundation \\ Andrew J. Houtenville \\ University of New Hampshire, Durham, andrew.houtenville@unh.edu \\ Debra L. Brucker \\ University of New Hampshire, Durham, debra.brucker@unh.edu
}

Follow this and additional works at: https://scholars.unh.edu/iod_chhs

\section{Recommended Citation}

Sevak, P., O'Neill, J., Houtenville, A. J., \& Brucker, D. (2016). State and Local Determinants of Employment Outcomes among Individuals with Disabilities. US Census Bureau Center for Economic Studies Paper No. CES-WP-16-21.

This Article is brought to you for free and open access by the College of Health \& Human Services (CHHS) at University of New Hampshire Scholars' Repository. It has been accepted for inclusion in Institute on Disability by an authorized administrator of University of New Hampshire Scholars' Repository. For more information, please contact Scholarly.Communication@unh.edu. 


\title{
State and Local Determinants of Employment Outcomes among Individuals with Disabilities
}

by

\author{
Purvi Sevak \\ Mathematica Policy Research
}

\author{
John O'Neill \\ Kessler Foundation
}

Andrew Houtenville

University of New Hampshire

Debra L. Brucker

University of New Hampshire

\begin{abstract}
CES 16-21
March, 2016

The research program of the Center for Economic Studies (CES) produces a wide range of economic analyses to improve the statistical programs of the U.S. Census Bureau. Many of these analyses take the form of CES research papers. The papers have not undergone the review accorded Census Bureau publications and no endorsement should be inferred. Any opinions and conclusions expressed herein are those of the author(s) and do not necessarily represent the views of the U.S. Census Bureau. All results have been reviewed to ensure that no confidential information is disclosed. Republication in whole or part must be cleared with the authors.

To obtain information about the series, see www.census.gov/ces or contact Fariha Kamal, Editor, Discussion Papers, U.S. Census Bureau, Center for Economic Studies 2K132B, 4600 Silver Hill Road, Washington, DC 20233, CES.Papers.List@census.gov. To subscribe to the series, please click here.
\end{abstract}




\begin{abstract}
In the United States, employment rates among individuals with disabilities are persistently low but vary substantially. In this study, we examine the relationship between employment outcomes and features of the state and county physical, economic, and policy environment among a national sample of individuals with disabilities. To do so, we merge a set of state- and countylevel environmental variables with data from the 2009-2011 American Community Survey accessed in a U.S. Census Research Data Center. We estimate regression models of employment, work hours, and earnings as a function of health conditions, personal characteristics, and these environmental features. We find that certain environmental variables are significantly associated with employment outcomes. Although the estimated importance of environmental variables is small relative to individual health and personal characteristics, our results suggest that these variables may present barriers or facilitators to employment that can explain some geographic variation in employment outcomes across the United States.
\end{abstract}

Keyword: Disability; employment; area effects.

Acknowledgement: This project was funded by the National Institute on Disability, Independent Living, and Rehabilitation Research (NIDILRR), U.S. Department of Health and Human Services (HHS) Rehabilitation and Research Training Center on Individual Characteristics, under cooperative agreement 90RT5017-01-01. The findings and conclusions are those of the authors and do not represent the policy of HHS or NIDILRR. The authors retain sole responsibility for any errors or omissions. Corresponding author: Purvi Sevak, Mathematica Policy Research, P.O. Box 2392, Princeton NJ, 08543-2393. Ph: 609-945-6596, Fax: 609-799-0005. psevak@mathematicampr.com 


\section{Introduction}

In the United States, employment rates among working-age individuals with disabilities have continuously been substantially lower than employment rates among individuals without disabilities. Among people age 16 and older, for example, 66 percent of those who did not have a disability and 23 percent of those who had a disability were employed in 2014 (U.S. Census Bureau 2015a). Economic disparities remain for people with disabilities who do work; for example, they earn less, on average, than people without disabilities (Yin et al. 2014). In 2014, median annual earnings among people with disabilities were $\$ 21,232$, substantially less than the median annual earnings of those without disabilities (\$31,324) (U.S. Census Bureau 2015b). Part of this difference may be due to the fact that workers with disabilities are less likely to work full time than those without disabilities (U.S. Census Bureau 2015c).

These employment outcomes vary substantially across states, suggesting that differences in state and local economic, policy, or other environmental characteristics may play an important role in shaping employment opportunities for people with disabilities. This variation also provides an opportunity to learn about factors that could improve employment outcomes for people with disabilities. To explore this issue, we combine data characterizing the state and local environment from a variety of sources with data on a large, nationally representative sample of individuals with disabilities included in the American Community Survey (ACS).

We find that a number of environmental variables are significantly associated with positive employment outcomes, but the magnitude of the relationship between any single variable and employment outcomes is small compared to the relationship between individual characteristics and employment outcomes. Our findings across a number of domains suggest that people living in poor, densely populated areas with high unemployment rates are less likely to be employed than those living in other types of environments. However, some urban environment 
characteristics are also associated with higher earnings. Although the estimated importance of environmental variables is small relative to that of individual health and personal characteristics, our results suggest that environmental factors may present barriers or facilitators to employment that can explain some of the geographic variation in employment outcomes across the United States.

\section{Background}

Employment rates among individuals with disabilities vary substantially across states. Rates for this population estimated from pooled 2009-2011 data range from a low of 25.3 percent employment in West Virginia to a high of 52.8 percent in North Dakota. Figure 1 illustrates the variation among states in employment rates for people with disabilities. The map in Figure 2 shows county-level employment rates, revealing that there is also substantial variation within states. For example, most counties in Arizona (including Pima County, where Tucson is located, and Maricopa County, where Phoenix is located) have medium shading indicating that the employment rates for this population are 30 to 40 percent. However Coconino County has employment rates higher than 40 percent and several counties have employment rates lower than 30 percent.

From a theoretical perspective, this variation is consistent with a social model of disability, which posits that an individual's medical condition or impairment, assistive devices, and characteristics of his or her physical, social, policy, and economic environments are major determinants of participation in social activities such as employment (Verbrugge and Jette 1994). If these environmental factors vary across states and counties, we would expect to find differences in employment outcomes. The International Classification of Functioning, Disability and Health (ICF) groups the determinants of employment into three domains that affect

outcomes: (1) underlying "health conditions,” (2) “personal characteristics,” and (3) 
“environmental characteristics.” We use this framework to review the existing literature and structure our analyses.

The literature provides substantial evidence of differences in employment by the first domain, health characteristics, using various national data sets. People with sensory impairments are more likely to be employed than those with physical impairments, and members of both of these groups are more likely to be employed than those with mental impairments (Brucker et al. 2015; Houtenville et al. 2013; Weathers and Wittenburg 2005; Wittenburg and Nelson 2006). Different employment rates by health condition are also documented among recipients of Social Security Disability Insurance (SSDI) (Maestas et al. 2013) and Supplemental Security Income (SSI) (Berry and Caplan 2010), and vocational rehabilitation (VR) clients (O’Neill et al. 2016).

A number of other studies also document differences by the second ICF domain, personal characteristics. Researchers have consistently found that older age is associated with lower employment rates in various national subpopulations of individuals with disabilities, including people with physical impairments or chronic health conditions (Ipsen 2006), SSDI and SSI participants (Mamun et al. 2011; Stapleton et al. 2010), participants in State Medicaid Buy-In programs (Ireys et al. 2009) and VR clients (Mwachofi et al. 2009). Research findings on gender, race, ethnicity, and employment outcomes have differed (Mwachofi et al. 2009; Ipsen et al. 2006; Ireys et al. 2009). However, recent work using a national sample of individuals with disabilities found that holding other factors constant, the employment gap between individuals with and without disabilities is smaller for those in their 20s and 60s than for the middle aged, for Asians than for Whites, for Hispanics than for non-Hispanics, for married individuals than for those who are not married, for people with higher levels of educational attainment, and for women (Sevak et al. 2015). 
In this study, we focus on the third ICF domain, environmental characteristics, and we divide these characteristics into four areas: (1) policy environment, (2) economic environment, (3) physical environment and amenities, and (4) population characteristics. Although this domain covers a vast set of factors, it has not been the subject of as much empirical research as the other domains.

The policy environment related to individuals with disabilities is shaped at the national level by programs such as SSDI or policies such as the Americans with Disabilities Act (ADA), at the state level by state VR programs, and by the interplay of both through programs such as SSI or Medicaid. Studies have documented positive and negative effects of the ADA (e.g., Acemoglu and Angrist 2001; DeLiere 2003; Beagle and Stock 2003) and of public disability benefit programs (e.g., Parsons 1980; Haveman and Wolfe 1984; Bound 1989; Chen and van der Klaauw 2008; von Wachter et al. 2011; Maestas et al. 2013; French and Song 2014) on employment. At the state level, a number of studies have documented associations between employment rates and differences in VR agencies and programs (Stapleton et al. 2010). Differences in rehabilitation rates-the percentage of people served by VR agencies who are employed when their case is closed-may reflect the availability of an adequate, wellcoordinated system of employment services and supports. Research shows that some states with Medicaid Buy-In programs have higher employment rates (Ireys et al. 2009). States' SSDI and SSI allowance rates also vary. These differences may reflect systemic variation in disability determination processes but also differences in state demographic or economic factors (Strand 2002). Recent work by Manchester (2015), for example, suggests that the high rates of SSDI participation by young adults in northern New England states can be attributed to a mixture of state policy and economic and population health factors. 
The local economic environment may affect the actual employment opportunities that are available. People with disabilities were disproportionately affected by the most recent recession (Livermore and Honeycutt 2015) and some studies have found that county-level per capita income (Botticello et al. 2012; Cunningham and Altman 1993) and employment rates (Cunningham and Altman 1993) were related to employment for selected subpopulations of individuals with disabilities. A related literature has shown how the local economy influences SSI or SSDI application. Nichols et al. (2014) found that county unemployment rates are related to adult SSI application, Autor and Duggan (2003) found that shifts in state-level labor demand predict changes in SSDI participation, and Black et al. (2002) found that local earnings growth is related to both SSDI and SSI participation.

The physical environment and local amenities may also present barriers or facilitators to individuals with disabilities. Transportation (Whiteneck et al. 2004), weather conditions (Wee and Paterson 2009), and personal safety (Brucker 2015) have all been reported as barriers to employment for various subpopulations of individuals with disabilities. Living in an urban area is associated with lower employment rates among individuals with spinal cord injuries (Botticello et al. 2012). One study found that individuals with disabilities living in areas with high levels of illegal drug use had poorer labor market outcomes (Richardson et al. 2013).

Our research constitutes an effort to move the literature forward by examining associations between a broad set of environmental characteristics and employment outcomes in a national sample of individuals with disabilities, to understand how those characteristics facilitate or impede employment. We hypothesize that employment outcomes for individuals with disabilities will vary with these characteristics, when holding health and personal characteristics constant. Because some environmental factors may be more malleable, understanding their relationship to employment outcomes is important for shaping policies that aim to improve employment 
outcomes for individuals with disabilities. The outcomes we examine include not only employment but also hours of work and earnings among individuals who are working, given the evidence that disparities exist even among those who are working (U.S. Census Bureau 2015b). In the next section, we describe the data and methods we employed to examine these three outcomes.

\section{Methods}

A. Data

Our sample included approximately 599,000 community-dwelling individuals with disabilities who were ages 25 to 59 in the 2009-2011 pooled ACS. The ACS, collected by the U.S. Census Bureau, is the largest nationally representative survey in the United States. It provides detailed demographic characteristics and information on employment and income annually. Researchers have used a sequence of six questions in the ACS that ask about vision, hearing, ambulatory, cognitive, self-care, and independent living difficulties to identify individuals with disabilities (Burkhauser et al. 2014). We used the pooled three-year file in order to have adequate sample sizes for individuals with disabilities at the county level.

Although the ACS contains detailed information on individual characteristics, it has limited information about the policy, economic, and social environment in which the respondents live. To augment the analysis file with this information, we compiled data on state and county environmental variables from a number of external sources. We discuss these measures and their respective sources in the next section. We merged the state and county variables with the ACS analysis file using state and county geocodes. The publicly available versions of the ACS do not fully report county of residence, so we used a restricted version of the data that is available only in U.S. Census Research Data Centers.

B. Model specification 
Using population weights provided in the ACS, we estimated linear regression models of three employment outcomes $E$ : employment, weekly hours of work, and earnings. $E_{i j}$ is the observed outcome of individual $i$ who lives in state and county $j$ and it is a function of his or her underlying health condition/disability type $\left(H_{\mathrm{ij}}\right)$, personal characteristics $\left(X_{\mathrm{ij}}\right)$, and a residual term $\left(e_{i j}\right)$ as follows:

$$
\begin{aligned}
& E_{i j}=f\left(H_{i j}, X_{i j}, e_{i j}\right), \\
& e_{i j}=u_{j}+\varepsilon_{i j} \text {, and } \\
& u_{j}=g\left(Z_{j}, v_{j}\right)
\end{aligned}
$$

$H$ includes six indicator variables for each of the six ACS disability questions. $X$ includes variables that have been shown in the literature to be related to labor supply, particularly labor supply of individuals with disabilities (Sevak et al. 2015), including gender, age, race and ethnicity, educational attainment, and marital and veteran's status.

In equation (1), the component of employment outcomes that cannot be explained by $H$ and $X$ is the residual $e$, which itself is composed of the effect of living in location $j$, $\left(u_{j}\right)$ and unobservable individual characteristics $\left(\varepsilon_{\mathrm{ij}}\right)$. The effect of living in location $j,\left(u_{j}\right)$ is a function of the observable environmental characteristics of location $j,\left(Z_{\mathrm{j}}\right)$ and a location-specific error term $\left(v_{j}\right)$. Table 1 contains the specific variables that make up $Z$ and their respective sources. We grouped these variables into four categories: policy environment, economic environment, physical environment and amenities, and population characteristics. We controlled for locationspecific unobservable characteristics using indicators for nine census divisions. ${ }^{1}$ Table 2 provides descriptive statistics for these measures.

\footnotetext{
${ }^{1}$ We also estimated the regressions with state fixed effects, without any state policy variables, and the estimates were similar. Estimates are available upon request.
} 
We included five measures of the policy environment, all but one of which are state-level characteristics. First, we included the rehabilitation rate in the state, which is the percentage of individuals who received employment services through the state VR agency and were employed when their case was closed. Higher rehabilitation rates may reflect a better system of employment supports and as a result we expect them to be associated with higher employment, hours, and earnings. The mean rehabilitation rate was 57.5 percent. Second, we included two measures related to Social Security disability benefits, which theoretically should be negatively associated with employment outcomes because they make receipt of disability benefits more likely or more attractive. The first, the allowance rate, with a mean of 26.5 percent, is the percentage of SSI and SSDI applicants who are approved to receive benefits. The second measure is the dollar amount of the state SSI supplement for individual recipients. Its mean, which includes states with no supplement, is $\$ 44$. We also included an indicator for whether the state has a Medicaid Buy-In program (MBI). The MBI program offers Medicaid coverage to people with disabilities who are working and are earning more than the allowable limits for regular Medicaid. Because the program is designed to encourage working people with disabilities to earn more income without the risk of losing vital health care coverage, we expect it to be positively associated with employment outcomes. Seventy percent of the sample members live in a state with a Medicaid Buy-In program. Lastly, we included the amount of federal aid per capita the county received, as a proxy for the fiscal health of the local government. We did not have a prior expectation on whether this variable would be related to employment rates, but we include it because there is evidence that state-level fiscal distress is related to SSI caseloads (Kubik 2003).

We included four county-level measures of the economic environment that capture slightly different features of the local economy. In general, we expected individuals living in counties 
with more robust economies to have better employment outcomes. We included the county poverty rate, which has a mean of 15.3 percent, as a measure of the economic well-being at the bottom of the income distribution. We also included the county unemployment rate, which has a mean of 9.6 percent, to describe labor market opportunities. Third, we included the labor force participation rate, which reflects labor supply and may reflect local variation in social norms regarding withdrawal from the labor force. Lastly, we included the percentage of jobs in blue collar industries as a measure of the composition of jobs in the county.

The third set of variables captures the physical environment and local amenities that may be facilitators or barriers to employment for individuals with disabilities. These include two measures of metropolitan status and density, mean county temperature in January, the percentage of workers who use public transportation to commute to work, the number of physicians per thousand people in the population, and the number of violent crimes per thousand people in the population.

Last, we included county-level population characteristics. These include measures of the distribution of age, race, and educational attainment. Although this paper does not focus on these characteristics, we controlled for them because both disability prevalence and employment outcomes vary by demographic characteristics and geography (Houtenville et al. 2013).

\section{Results}

\section{A. Employment.}

Table 3 provides coefficients and t statistics from a linear regression model encompassing equations 1,2 and 3 of a dichotomous measure of employment that equals one if the individual is employed and zero otherwise. Estimates can be interpreted as percentage point differences in the probability of employment associated with incremental differences in the explanatory variable, when controlling for all other measures of environmental and individual characteristics. The 
regression also includes controls for the nine census divisions to absorb regional differences in employment.

The regression estimates show a number of environmental variables are statistically significant predictors of employment, but in general the magnitudes are small. We discuss the results by the four categories of environmental variables, followed by results for individual characteristics.

Among the policy variables, only the state SSI supplement is associated with significant differences in employment. This effect is small, however, with the coefficient magnitude implying that an individual living in a state with an SSI supplement that was $\$ 100$ higher than average was 0.0077 less likely to be employed. This estimate is about 2 percent of the overall employment rate of 37 percent. Differences in the rehabilitation rate, allowance rate, presence of a MBI program, and federal expenditures are not associated with statistically significant differences in employment rates.

All four of the economic variables have statistically significant coefficients that are larger than those for the policy variables. To get a richer sense of the magnitudes of the regression estimates, we discuss the magnitude of a 20 percent higher value of the explanatory variable. We calculated this by taking 20 percent of the mean value of the explanatory variable, and multiplying it by the regression coefficients. A 20 percent higher poverty rate (e.g., a rate of 18 percent rather than the mean of 15 percent) is associated with a -0.006 percentage point lower employment rate, which is 1.6 percent of the mean employment rate of 37 percent. A 20 percent higher unemployment rate is associated with 2 percent lower employment rate, while a 20 percent higher labor force participation rate is associated with a 12.6 percent higher employment rate. Individuals living in counties where a larger share of jobs are in blue collar industries were also significantly more likely to be employed, but the magnitude is very small. 
We found that a number of amenities and characteristics of the physical environment were associated with significant differences in employment rates for people with disabilities. Higher population densities, higher concentrations of physicians, and higher rates of violent crime were associated with lower employment rates. Although the estimated magnitudes for physicians and violent crime were very small, the estimated magnitude for population density was very large. A 20 percent lower population density was associated with employment rates more than double the mean rate. The coefficient on metropolitan area was not significant, but the results for density, physicians, and violent crime together paint a picture of lower employment rates in large urban areas.

Three of the population measures that we considered were significantly associated with differences in employment rates. Individuals living in counties where the White proportion of the population was 20 percent lower were about 3 percent more likely to be employed. It is not clear what accounts for this relationship but counties with a more diverse population may be better prepared to include individuals with disabilities in their already diverse labor force. Counties with a larger proportion of Hispanic people had significantly higher employment rates for people with disabilities but the implied magnitude was miniscule. A 20 percent larger share of college graduates was associated with a one percent higher employment rate.

In contrast to the small coefficients for environmental characteristics, the estimated coefficients for individual characteristics reported at the bottom of Table 3 are quite large. There were significant differences in employment by specific types of disability, gender, age, race, ethnicity, educational attainment, and marital and veteran's status. These estimates are consistent with findings in Sevak et al. (2015) and we report them here mainly to provide a contrast and context for the estimated coefficients on the environmental variables.

B. Hours and Earnings 
Table 4 presents results from separate regressions of hours of work and earnings among individuals who are working. We estimated both of the regressions using the natural log of the dependent variable so coefficient estimates tell us the percentage change in hours or earnings associated with a unit difference in the explanatory variable. As with our discussion of the magnitude of coefficients in the employment regression, we discuss magnitude with respect to a 20 percent difference in continuous explanatory variables.

Several policy variables were significant predictors of hours of work and earnings, but again the magnitudes were generally small. The state SSI supplement was significantly and negatively associated with hours of work but the magnitude was close to zero and it had no significant relationship with earnings. Workers in states with a Medicaid Buy-in program had 2 percent higher earnings but did not have significantly different hours of work. Higher federal expenditures were positively and significantly associated with both hours and earnings but the implied magnitude was also close to zero.

Unlike the findings for employment, for the county economic characteristics only the poverty rate had a significant relationship with hours and earnings. Individuals in counties with a 20 percent higher poverty rate worked one percent fewer hours and had 6 percent lower earnings. Neither the unemployment rate, participation rate, nor blue collar share was associated with significant differences in hours or earnings.

Many of the physical environment and amenity variables were statistically significant in either the hours or earnings regression but again the estimates were generally small. In some cases, variables associated with larger urban environments were associated with better outcomes-for example, individuals living in counties with a metropolitan area earned 1.9 percent more and those living in counties with a higher percentage of individuals using public transportation earned more. As with employment, a higher concentration of physicians was 
associated with poorer employment characteristics. Interestingly, higher temperatures were associated with both more hours worked and higher earnings. The regressions controlled for nine Census divisions so these estimates should not be reflecting regional differences.

Lastly, we found a number of significant associations of varying magnitude between population characteristics and hours and earnings. Hours of work varied significantly but marginally with the percentage of the population that was elderly, White, or Hispanic. Earnings were also lower in counties with a larger share of elderly or White residents. Oddly, a 20 percent higher concentration of high school graduates was associated with 5 percent fewer hours worked and 15 percent lower earnings. Earnings were slightly higher with a greater concentration of college graduates. As with the coefficient estimates for the employment regression, coefficient estimates for individual characteristics were large, though they are not presented here.

\section{Subgroup Analyses}

The fact that a number of environmental variables are significant but small predictors of employment outcomes suggests that there may be some subpopulations for whom these characteristics matter more. To examine whether the estimated relationship between covariates and employment outcomes varies by type of disability, we estimated regressions of employment, hours and earnings, separately for individuals who report affirmatively to each of the six ACS disability questions. We do not include these estimates in the paper due to complex Census disclosure constraints regarding release of output for multiple subgroups, but in general the estimates were small, like the coefficient estimated on the full sample. In some cases, magnitudes were slightly larger for individuals with one type of disability and smaller and not significant for individuals with other types of disabilities. Some exceptions stand outemployment outcomes of individuals with ambulatory disabilities were most related to the environmental variables. Specifically, living in a state with a Medicaid Buy-In program was 
significantly associated with employment and higher earnings only for individuals with ambulatory disabilities. The estimated relationship between higher earnings and living in metro areas was also much larger among individuals with ambulatory disabilities. As a whole, few of the contextual variables were significant predictors among individuals with hearing and vision disabilities, the two groups with substantially higher employment rates (Houtenville et al. 2013).

\section{Discussion}

Our research explores state and county factors that could explain the substantial variation in employment outcomes across geographic areas among individuals with disabilities. We hypothesized that differences in state and local economic, policy, or other environmental characteristics may play important roles in shaping employment opportunities for people with disabilities. Our results suggest that differences in the economic, policy, and physical environments across states and counties are associated with some, albeit small, differences in employment outcomes for people with disabilities.

Differences in employment outcomes correlated with state differences in policies and practices would point to avenues for improving employment outcomes for individuals with disabilities. We found several policy variables are significant. First, a higher state SSI supplement is associated with slightly lower employment rates and fewer hours worked among those who work. Second, consistent with Ireys (2006), who found that Medicaid Buy-in was associated with higher employment rates, we found that Medicaid Buy-in is associated with slightly higher earnings, especially for individuals with ambulatory disabilities. Because the Medicaid Buy-in program is in place to ameliorate the disincentive effects on employment of Medicaid eligibility, it is encouraging that it is associated with higher earnings. Lastly, individuals in states with higher levels of federal expenditure work significantly more hours and earn more. 
Our findings across the economic and physical environment paint a picture that suggests individuals living in poor, densely populated areas with high unemployment rates are less likely to be employed. Urban amenities like public transportation and number of physicians that could facilitate employment are actually associated with lower rates of employment. However, among individuals who are employed, living in a metropolitan area and some urban characteristics such public transportation are associated with higher earnings. The fact that the relationship between these variables is positive for one employment outcome and negative for another seems counterintuitive. However, the factors associated with higher earnings may restrict labor demand and hence be associated with lower rates of employment.

One variable with a particularly large estimated relationship with employment is the county labor force participation rate. This rate is calculated among all working-age individuals—with and without disabilities—-but it is heavily weighted by the larger number of individuals without disabilities. Although the unemployment rate is generally used as a measure of labor demand, the participation rate reflects labor supply. Our finding that individuals with disabilities are more likely to be working if they living in an area where a larger share of all people work could be due to social norms that encourage employment.

In conclusion, our study found that a number of environmental characteristics are associated with significant differences in employment outcomes, though none of them are as strongly associated with outcomes as individual health and personal characteristics. Our results should not be interpreted to suggest that economic factors and policies are of minimal importance and cannot substantially improve employment outcomes. It may be that the conditions that would improve outcomes substantially did not exist in any of the counties during the time period we observed. It may also be that conditions matter more for some subgroups than for others, such as individuals with ambulatory impairments. Future research should examine whether economic 
conditions, policies, and other features of the environment may matter more for some subgroups or individuals than they do for others. 


\section{References}

Acemoglu, D., and Angrist, J., 2001. Consequences of employment protection? The case of the Americans with Disabilities Act, Journal of Political Economy 109(5), 915-957.

Autor, D. H., and Duggan, M., 2010. Supporting work: A proposal for modernizing the U.S. disability insurance system. A paper jointly released by The Center for American Progress and The Hamilton Project.

Beagle, K., and Stock, W.A., 2003. The labor market effects of disability discrimination laws. Journal of Human Resources, 38(3), 807-859.

Berry, H.G., and Caplan, L.J., 2010. Employment and earnings among transition-age Supplemental Security Income program participants. Journal of Disability Policy Studies 21(3), 152-159.

Black, D., Daniel, K., and Sanders, S., 2002. The impact of economic conditions on participation in disability programs: Evidence from the coal boom and bust. American Economic Review 92(1), 27-50.

Bound, J., 1989. The health and earnings of rejected disability insurance applicants. American Economic Review, 79(3), 482-503.

Botticello, A.L., Chen, Y., and Tulsky, D.S., 2012. Geographic variation in participation for physically disabled adults: The contribution of area economic factors to employment after spinal cord injury. Social Science \& Medicine, 75, 1505-1513.

Brucker, D.L., 2015. Perceptions, behaviors and satisfaction related to public safety for person with disabilities in the United States. Criminal Justice Review, 40(4). DOI: 10.1177/073416815584997.

Brucker, D.L., Houtenville, A.J., and Lauer, E.A., 2015. Using sensory, functional and activity limitation data to estimate employment outcomes for working-age persons with disabilities in the U.S. Journal of Disability Policy Studies. DOI: 10.1177/1044207315578949.

Burkhauser, R. V., Houtenville, A.J., and Tennant, J., 2014. Capturing the elusive working-age population with disabilities: Reconciling conflicting social success estimates from the Current Population Survey and American Community Survey. Journal of Disability Policy Studies, 24 (4), 195-205.

Chen, S., and van der Klaauw, W., 2008. The work disincentive effects of the disability insurance program in the 1990s. Journal of Econometrics, 142(2), 757-784.

Cunningham, P.J., and Altman, B., 1993. The effects of sociodemographic and contextual factors on employment of persons with mental retardation living in residential facilities. Journal of Development and Physical Disabilities, 5(4), 281-296. 
DeLeire, T., 2003. The Americans with Disabilities Act and the employment of people with disabilities. In The Decline in the Employment of People with Disabilities: A Policy Puzzle, edited by Richard V. Burkhauser and David C. Stapleton. Kalamazoo, MI: Upjohn Institute.

French, E., and Song, J., 2014. The effect of disability insurance receipt on labor supply. American Economic Journal: Economic Policy, 6(2), 291-337.

Haveman, R., and Wolfe, B., 1984. Disability transfers and early retirement: A casual relationship? Journal of Public Economics, 24(1), 47-66.

Houtenville, A., Sevak, P., O’Neill, J.,and Cardoso, E., 2013. Disability, prevalence and economic outcomes. In Career Development, Employment and Disability: From Theory to Practice, edited by D. Strauser. New York: Springer, 2013.

Ipsen, C., 2006. Health, secondary conditions, and employment outcomes for adults with disabilities. Journal of Disability Policy Studies, 17(2), 77-87.

Ireys, H.T., Gimm, G., and Liu, S., 2009. The effects of state policy decisions on the employment and earnings of Medicaid Buy-In participants in 2006. Journal of Disability Policy Studies, 20(3), 142-154.

Kubik, J. 2003. Fiscal federalism and welfare policy: The role of states in the growth of child SSI. National Tax Journal, 56(1), 61-79.

Livermore, G.A., and Honeycutt, T.C., 2015. Employment and economic well-being of people with and without disabilities before and after the Great Recession. Journal of Disability Policy Studies, 26(2), 70-79.

Maestas, N., Mullen, K.J., and Strand, A., 2013. Does disability insurance receipt discourage work? Using examiner assignment to estimate causal effects of SSDI receipt. American Economic Review, 103(5), 1797-1829.

Mamun, A., O’Leary, P., Wittenburg, D., and Gregory, J., 2011. Employment among social security disability program beneficiaries, 1996-2007. Social Security Bulletin, 71(3), 11-34.

Manchester, J., 2015. Why is the prevalence of young people on the Social Security Disability program in northern New England so high, and why has it risen so rapidly since 2000? Montpelier, VT: Vermont Legislative Joint Fiscal Office.

Mwachofi, A.K., Broyles, R., and Khaliq, A., 2009. Factors affecting Vocational Rehabilitation intervention outcomes: The case for minorities with disabilities. Journal of Disability Policy Studies, 20(3), 170-177.

Nichols, A., Schmidt, L., and Sevak, P., 2014. Economic conditions and Supplemental Security Income applications. Michigan Retirement Research Center Working Paper 2014-318.

O’Neill, J., Kaczetow, W., and Pfaller, J., 2016. Differences in vocational rehabilitation outcomes by health conditions and individual characteristics. Unpublished manuscript. 
Parsons, D., 1980. The decline in male labor force participation. Journal of Political Economy, 88(1), 117-134.

Richardson, L., Wood, E., and Keer, T., 2013. The impact of social, structural and physical environmental factors on transitions into employment among people who inject drugs. Social Science and Medicine, 76, 126-133.

Sevak, P., Houtenville, A.J., Brucker, D.L., \& O’Neill J., 2015. Individual characteristics and the disability employment gap. Journal of Disability Policy Studies, 26(2), 80-88.

Stapleton, D., Honeycutt, T., and Schechter, B., 2010. Closures are the tip of the iceberg: Exploring the variation in state vocational rehabilitation program exists after service receipt. Journal of Vocational Rehabilitation, 32(1), 61-76.

Strand, A., 2002. Social Security disability characteristics: Assessing the variation in allowance rates. Baltimore, MD: Social Security Administration. https://www.ssa.gov/policy/docs/workingpapers/wp98.html.

U.S. Census Bureau., 2015a. 2014 American Community Survey, 1-year estimates. Washington, DC: U.S. Census Bureau.

U.S. Census Bureau, 2015b. 2014 American Community Survey, 1-year estimates. B18140. Median earnings in the past 12 months (in 2014 inflation adjusted dollars) by disability status by sex for the civilian noninstitutionalized population 16 years and over with earnings. Washington, DC: U.S. Census Bureau.

U.S. Census Bureau, 2015c. 2014 American Community Survey, 1-year estimates. B23023. Sex by disability status by work status in the past 12 months by usual hours worked per week in the past 12 months. Washington, DC: U.S. Census Bureau.

Verbrugge, L.M., and Jette, A.M., 1994. The disablement process. Social Science and Medicine, 38(1), 1-14.

von Wachter, T., Song, J., and Manchester, J., 2011. Trends in employment and earnings of allowed and rejected applicants to the Social Security Disability Insurance Program. American Economic Review, 101(7), 3308-3329.

Weathers, R., and Wittenburg, D.C., 2009. Employment. In Counting Working-Age People with Disabilities: What Current Data Tell Us and Options for Improvement, edited by Andrew J. Houtenville, David C. Stapleton, Robert Weathers, and Richard V. Burkhauser. Kalamazoo, MI: Upjohn Institute.

Wee, J. and Paterson, M. 2009. Exploring how factors impact the activities and participation of persons with disability: Constructing a model through grounded theory. The Qualitative Report, 14(1), 165-200.

Whiteneck, G, Meade, M.A., Dijkers, M., Tate, D.G., Bushnik, T., and Forchheimer, M.B. 2004. Environmental factors and their value in participation and life satisfaction after spinal cord injury. Archives of Physical Medicine and Rehabilitation, 85(11), 1793-1803. 
Wittenburg, D. C., and Nelson, S., 2006. A guide to disability statistics from the Survey of Income and Program Participation. Ithaca, NY: Rehabilitation Research and Training Center on Disability Demographics and Statistics, Cornell University.

Yin, M., Shaewitz, D., and Megra, M., 2014. An unequal playing field: The lack of equal pay for people with disabilities. Washington, DC: American Institutes for Research. 
Figure 1: Employment Rates among Individuals with Disabilities, by State

State Employment Rate Among Working Aged Individuals with Disabilities

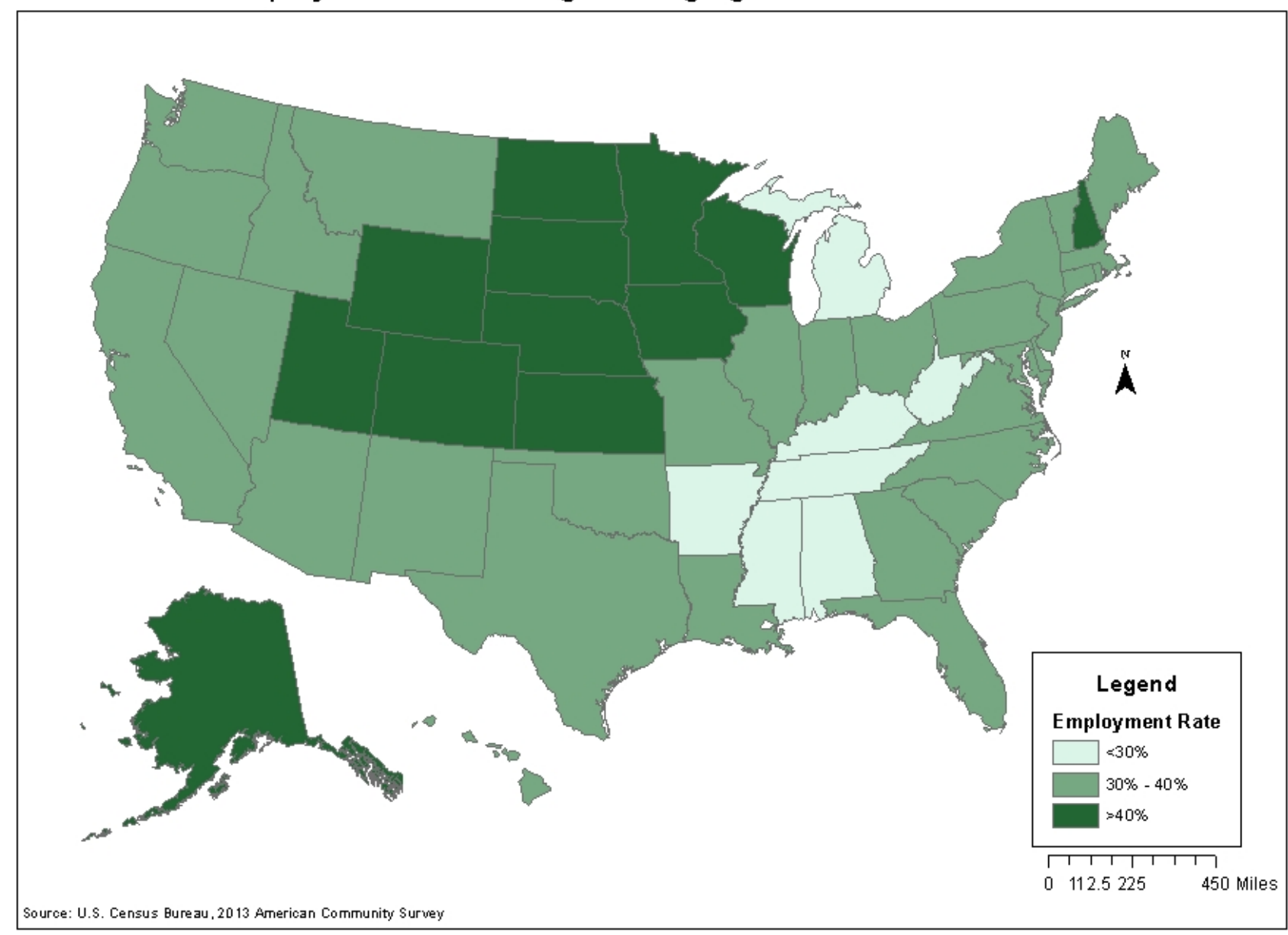


Figure 2: Employment Rates among Individuals with Disabilities, by County

County Employment Rate Among Working Aged Individuals with Disabilities

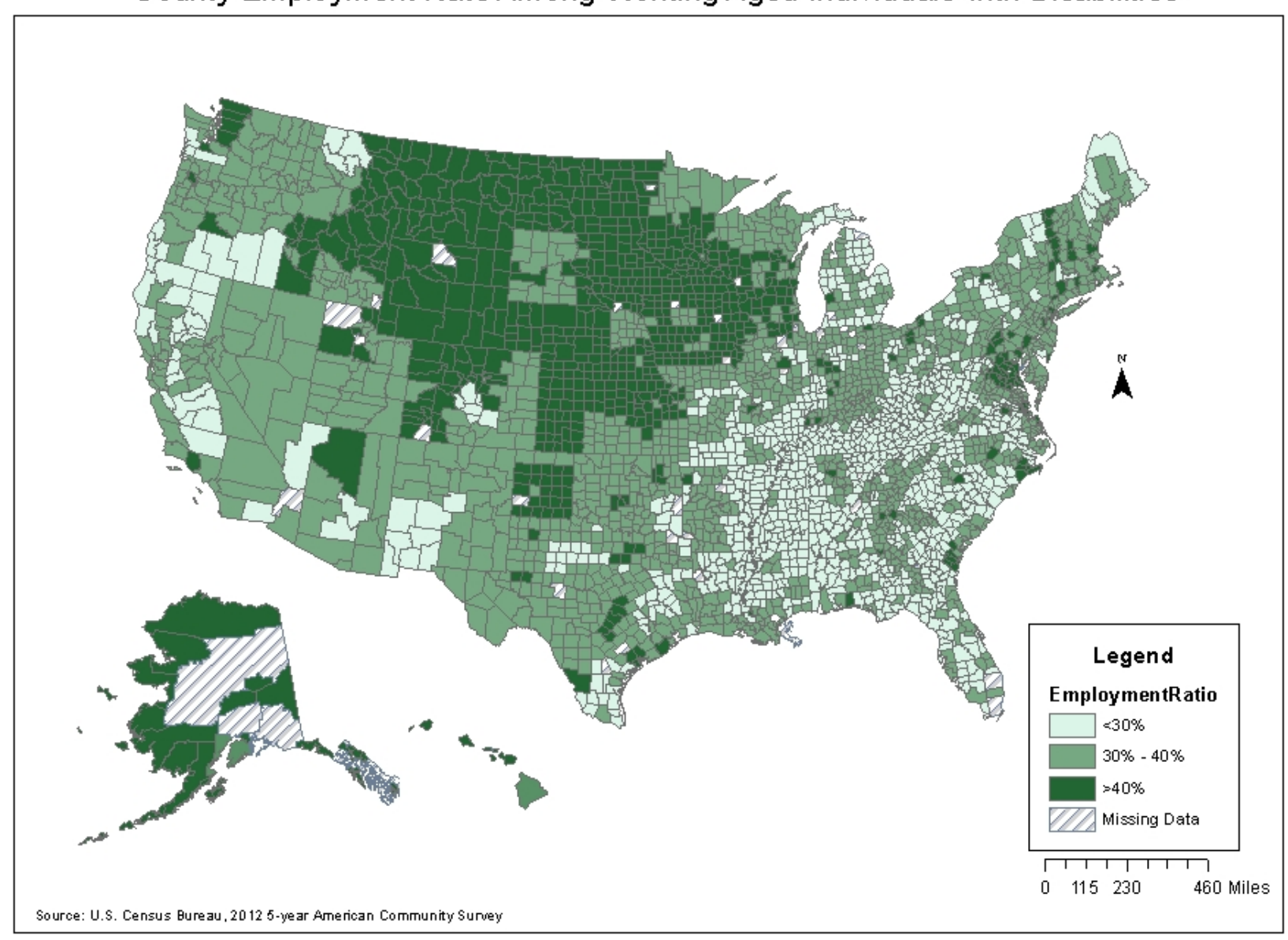




\section{Table 1: Variable Definitions and Sources}

\begin{tabular}{|c|c|c|c|}
\hline Variable & Definition & Year & Source \\
\hline \multicolumn{4}{|c|}{ Policy Environment (State level, except where noted) } \\
\hline Rehabilitation rate & $\begin{array}{l}\text { Percent of VR cases closed with } \\
\text { employment }\end{array}$ & 2008 & RSA 911 Case Closure Data \\
\hline SSDI/SSI allowance rate & $\begin{array}{l}\text { Percent of SSI and SSDI applicants } \\
\text { approved }\end{array}$ & 2008 & SSA Workload Data \\
\hline SSI supplement & State individual SSI supplement & 2010 & SSA \\
\hline MBI & State has Medicaid Buy-In program & 2008 & Mathematica Policy Research \\
\hline Federal expenditures & $\begin{array}{l}\text { Federal expenditures per capita in } \\
\text { county }\end{array}$ & 2004 & City and County Data Book \\
\hline \multicolumn{4}{|c|}{ Economic Environment (county level) } \\
\hline Poverty rate & Poverty rate & 2007-2011 & American Community Survey \\
\hline Unemployment rate & Unemployment rate & 2009 & Bureau of Labor Statistics, LAUS \\
\hline Participation rate & Labor force participation rate & 2007-2011 & American Community Survey \\
\hline Blue collar & Share of jobs in blue collar industries & 2010 & Census Business Patterns \\
\hline \multicolumn{4}{|c|}{ Physical Environment and Amenities (county level) } \\
\hline Metro & Contains a metropolitan area & 2000 & USDA Economic Research Service \\
\hline Density & Population density & 2010 & U.S. Census of Population \\
\hline Jan. temperature & Mean temperature in January & $1941-1970$ & USDA Economic Research Service \\
\hline Public transport & $\begin{array}{l}\text { Percent of employed population } \\
\text { commuting via public transportation }\end{array}$ & $2007-2011$ & American Community Survey \\
\hline Physicians & $\begin{array}{l}\text { Number of physicians per } 1,000 \\
\text { population }\end{array}$ & 2010 & Area Health Resources File \\
\hline Violent crime & $\begin{array}{l}\text { Number of violent crimes per } 1,000 \\
\text { population }\end{array}$ & $2008-2010$ & Dept. of Justice Violent Crime Reports \\
\hline \multicolumn{4}{|c|}{ Population Composition (county level) } \\
\hline Children & $\begin{array}{l}\text { Percent of population aged } 14 \text { and } \\
\text { under }\end{array}$ & 2010 & U.S. Census of Population \\
\hline Elderly & $\begin{array}{l}\text { Percent of population aged } 65 \text { and } \\
\text { older }\end{array}$ & 2010 & U.S. Census of Population \\
\hline White & Percent of population of White race & 2010 & U.S. Census of Population \\
\hline Hispanic & $\begin{array}{l}\text { Percent of population of Hispanic } \\
\text { ethnicity }\end{array}$ & 2010 & U.S. Census of Population \\
\hline High School plus & $\begin{array}{l}\text { Percent of population with education } \\
\text { attainment of HS grad or more }\end{array}$ & 2007-2011 & American Community Survey \\
\hline Bachelors' plus & $\begin{array}{l}\text { Percent of population with education } \\
\text { attainment of Bachelor's degree or } \\
\text { more }\end{array}$ & $2007-2011$ & American Community Survey \\
\hline
\end{tabular}


Table 2: Means of Environmental Variables Among Individuals with Disabilities ages 25 to 59

\begin{tabular}{lcc}
\hline & Mean & Std. Dev. \\
Policy Environment (State level, except where noted) & \\
Rehab rate (\%) & 57.5 & 8.6 \\
SSDI/SSI allowance rate (\%) & 26.5 & 3.1 \\
SSI supplement & 44.3 & 88.4 \\
MBI & 0.7 & 0.5 \\
Federal exp. & 6,953 & 4,671 \\
Local rev. & 3,345 & 1,793 \\
Economic Environment (county level) & & \\
Poverty rate (\%) & 15.3 & 5.3 \\
Unemployment rate (\%) & 9.6 & 2.6 \\
Participation rate (\%) & 63.2 & 6.1 \\
Blue collar (\%) & 14.9 & 4.3 \\
Physical Environment and Amenities (county level) & & \\
Metro & 0.8 & 0.4 \\
Urban infrastructure & 2.5 & 2.4 \\
Density & 991 & 2,339 \\
Jan. temperature & 37.5 & 12.1 \\
Public transport (\%) & 3.3 & 6.6 \\
Physicians & 0.7 & 0.3 \\
Violent crime & 72.9 & 129.6 \\
Population Composition (county level) & & \\
Children (\%) & 19.8 & 2.6 \\
Elderly (\%) & 13.5 & 3.5 \\
White (\%) & 74.2 & 16.4 \\
Hispanic (\%) & 84.6 & 9.2 \\
High School plus (\%) & 25.6 \\
Bachelors' plus (\%) & 10.3 & 9.6 \\
Foreign born (\%) & & \\
& & \\
\hline
\end{tabular}

Source: The sample includes individuals ages 25 to 59 who reported one or more of six disabilities in the 2009-2011 Three-Year American Community Survey. Estimates are weighted. 
Table 3: Estimates from Employment Regressions Among Individuals with Disabilities

\begin{tabular}{|c|c|c|}
\hline & Coefficient & t statistic \\
\hline \multicolumn{3}{|c|}{ Policy Environment (State level, except where noted) } \\
\hline Rehab rate & 0.0001 & 0.96 \\
\hline SSDI/SSI allowance rate & 0.0001 & 0.23 \\
\hline SSI supplement (\$100s) & -0.0077 & -2.94 \\
\hline MBI & 0.0036 & 1.26 \\
\hline Federal exp. $(\$ 1,000 s)$ & 0.0004 & 0.98 \\
\hline \multicolumn{3}{|c|}{ Economic Environment (county level) } \\
\hline Poverty & -0.0019 & -4.90 \\
\hline Unemployment & -0.0044 & -7.91 \\
\hline Participation rate & 0.0037 & 9.93 \\
\hline Blue collar & 0.0008 & 2.44 \\
\hline \multicolumn{3}{|c|}{ Physical Environment and Amenities (county level) } \\
\hline Metro & -0.0034 & -1.09 \\
\hline Density & -0.0037 & -2.65 \\
\hline Jan. temperature & -0.0003 & -1.87 \\
\hline Public transport & -0.0005 & -1.73 \\
\hline Physicians & -0.0155 & -2.95 \\
\hline Violent crime & -0.0000 & -1.98 \\
\hline \multicolumn{3}{|c|}{ Population Composition (county level) } \\
\hline Children & -0.0006 & -0.87 \\
\hline Elderly & 0.0006 & 1.11 \\
\hline White & -0.0007 & -6.67 \\
\hline Hispanic & 0.0005 & 3.65 \\
\hline High School plus & 0.0000 & 0.06 \\
\hline Bachelors' plus & 0.0009 & 3.61 \\
\hline \multicolumn{3}{|l|}{ Individual Characteristics } \\
\hline Cognitive disability & -0.1459 & -88.13 \\
\hline Ambulatory disability & -0.1365 & -56.11 \\
\hline Independent living disability & -0.1915 & -99.34 \\
\hline Self-care disability & -0.0354 & -16.76 \\
\hline Blind or visually impaired & 0.0218 & 9.96 \\
\hline Deaf or hearing impaired & 0.1022 & 44.22 \\
\hline Female gender & -0.0351 & -20.08 \\
\hline Age 25-34 & 0.0216 & 5.85 \\
\hline Age 40-49 & -0.0187 & -7.64 \\
\hline Age 50-59 & -0.0697 & -29.58 \\
\hline Black race & -0.037 & -11.23 \\
\hline Asian race & 0.0052 & 0.83 \\
\hline Other race & -0.0040 & -1.00 \\
\hline Hispanic ethnicity & 0.0352 & 8.69 \\
\hline
\end{tabular}




\begin{tabular}{lcc}
\hline & Coefficient & t statistic \\
Educ. 9th-12th grade & 0.0076 & 2.47 \\
Educ. HS grad & 0.085 & 28.94 \\
Educ. some college & 0.1332 & 42.03 \\
Educ. Assoc. degree & 0.1847 & 43.26 \\
Educ. Bachelor's degree & 0.24 & 57.95 \\
Educ. postgrad degree & 0.3073 & 70.5 \\
$\quad$ Veteran & -0.0247 & -8.99 \\
$\quad$ Married & 0.0571 & 37.11 \\
Constant & 0.3395 & 6.19 \\
R-squared & 0.20 & \\
$\mathrm{n} \quad$ Percent Employed & 599,000 & \\
\hline
\end{tabular}

Source: The sample includes individuals ages 25 to 59 who reported one or more of six disabilities in the 2009-2011 Three-Year American Community Survey. Regression is estimated using weights and controls for nine Census divisions. 
Table 4: Estimates from Hours and Earnings Regressions Among Employed Individuals with Disabilities

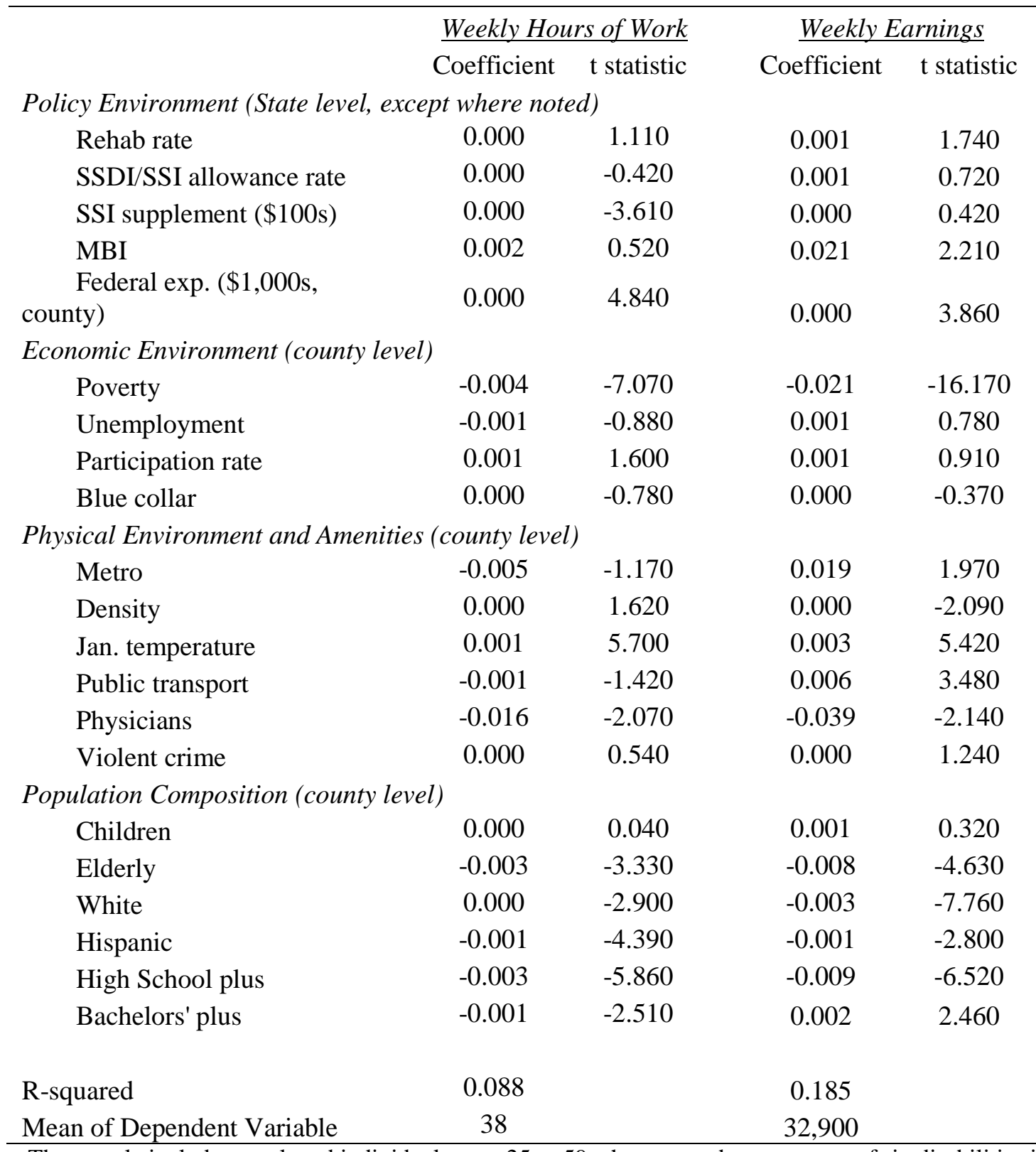

Source: The sample includes employed individuals ages 25 to 59 who reported one or more of six disabilities in the 2009-2011 Three-Year American Community Survey. Regressions are estimated using weights and controls for nine Census divisions and the individual characteristics listed in Table 3. The dependent variable is measured in the natural log and coefficient estimates can be interpreted as percentages. 